\title{
Optimization of Osmo- Dehydration Process of Honey-Ginger Candy by using Response Surface Methodology
}

\author{
S Elizabeth Amudhini Stephen, Vignesh Kumar.E
}

\begin{abstract}
This report is to investigate the effects of process variables on the solid gain, water loss using the Response surface methodology (RSM). The ginger was Osmo-dehydrated using process variables such has blanching time, the temperature for an osmotic solution, immersion, \& convective drying temperature .response variables tested were solid gain and water loss. The blanching is done to inactivate the enzyme and to increase permeability in ginger candy. The optimum Osmo-convective process conditions for a maximum solid gain, water loss, and overall acceptability of honey-ginger candy were $8.39 \mathrm{~min}$ blanching time, $39^{\circ}$ Csolution temperature, $94 \mathrm{~min}$ immersion time, and $70^{\circ} \mathrm{C}$ convective drying temperature.
\end{abstract}

Keywords: Osmo-dehydration, optimization, honey ginger candy, RSM

\section{INTRODUCTION}

Ginger (Zingiber officinale Roscoe, Zingiberaceae) is an herbaceous, rhizomatous, perennial plant and has been traditionally used in many cuisines to stimulate human senses with exotic flavors and burning, heat sensations since time immemorial. The active constituents such as gingerols and shogaols play a primary role in the pungency of fresh and dried ginger. [1-2] More than 60 nutraceuticals have been isolated and characterized by ginger, including terpenoids, isotereprnoids, and polyphenols and these compounds are primarily responsible for the therapeutic, anti-oxidative properties, anti-bacterial and sensory attributes. [3] It has been reported by various researchers that, long-term use of ginger has an intense effect incurring many diseases, but the pungent taste of ginger limits its direct use. Therefore, there is a need for techno-economic alternate processes to develop ginger-based, Ready-to-eat products. Osmotic dehydration is one of these methods for the utilization of ginger. $[5,6]$ Osmotic dehydration is used for the partial removal of water from plant tissues by immersion in a hypertonic solution to obtain a product with a better shelf life, which is ready-to-eat, or just as a pre-processing to drying, freezing, pasteurization, and canning. [5, 7] Leaching of natural solutes present in the

Revised Manuscript Received on April 11, 2020.

* Correspondence Author

S,Elizabeth Amudhini Stephen*, Associate Professor, Department of Mathematics, Karunya Institute of Technology and Sciences, Coimbatore, India. elizi.felix@gmail.com

Seihenbal,G,S, Department of Food Processing, Karunya Institute of Technology and Sciences, Coimbatore

(C) The Authors. Published by Blue Eyes Intelligence Engineering and Sciences Publication (BEIESP). This is an open access article under the CC BY-NC-ND license (http://creativecommons.org/licenses/by-nc-nd/4.0/) material also takes place during osmotic dehydration, which is quantitatively negligible. [8] It has been investigated by many authors that, the effect of temperature and solution concentration on the kinetics of the osmotic dehydration of different food materials. The osmotic dehydration process mainly depends on the microstructure of tissue, the surface to volume ratio, and pretreatments (Peeling, blanching, freeze-thawing,etc.).

Honey is advertised as one of the most "natural" products consumed in the United States. As the National Honey Board (NHB) states "honey is honey. It's just that simple." According to the NHB, an organization responsible for honey "marketing and promotion," pure honey contains only the "natural sweet substance produced by honey bees from the nectar of plants or the secretions of living parts of plants. "As stated by Rowan Jacobsen, author of a recent book about the collapse of honey bees in the United States, bees "have an inestimable intelligence wholly unlike the human variety and well worth comprehending." Bees not only provide honey, they also play an integral role in producing the food consumed in the U.S., with "at least $30 \%$ of agriculture" relying directly on their pollination services as of 2010 Along those lines, Ross Conrad, author of Natural Beekeeping, writes "We can learn so much from the honey bee... of all the insects, the honey bee seems to lend itself most perfectly to anthropomorphism... [since it] contributes directly to the abundance found on Earth." By providing an overview of activity within the beehive, describing basic small-scale and large-scale beekeeping methodology, honey processing, and the differences between "conventional" and "organic" honey production, this paper aims to provide U.S. consumers insight into the process that transforms nectar into the sweet substance purchased in bottles at farmers markets and grocery stores, or contained in products such as Honey Nut Cheerios.

The honey harvest usually occurs in fall; after all, honey frames have been filled and capped; although in some regions, where nectar is particularly abundant, two honey harvests can be expected. To access the hive, both for the general care and honey harvest, a smoker must be used to prevent bees from attacking. Because bees start eating honey when exposed to smoke, perhaps an adaptation to protect themselves from forest fires, smoking the hive will distract them from the beekeeper intruding into their hive. Bees can be removed from full honey supers using a variety of methods ranging from gently brushing them off, to blowing with a modified leaf blower. After removing honey-filled frames the honey needs to be extracted from the honeycomb.

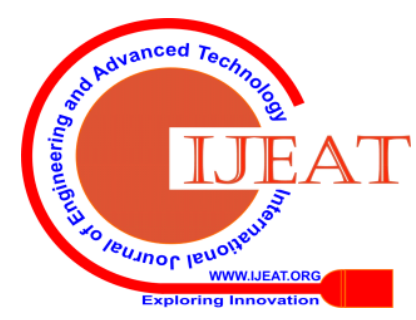


Like the hive, a honey house has a ventilation system to keep the honey properly dehydrated. Small-scale beekeepers use a knife, usually heated, to cut off the wax capping, while larger-scale beekeepers may use a more advanced machine.

The frames are then placed into a honey extractor, which is around, keg shaped machine that uses centrifugal force to expel the honey from the honeycomb. According to the experts quoted on Beesource.com, an active online beekeeping community, "as soon as the honey is removed from its sealed state, deterioration begins" so it must be handled extremely carefully from extraction onwards.

\section{MATERIALS AND METHODS}

\section{Raw material}

Ginger and honey are purchased in market

\section{Preparation of Sample and Osmotic Dehydration:}

Ginger is washed with tap water, peeled and cut $(0-5 \mathrm{~cm} * 0.5 \mathrm{~cm} * 0.5 \mathrm{~cm})$ Cubes blanched in the surface was removed using filter paper. In Convective Dehydration: The samples were dried at a selected temperature in a cross-flow drier the dried samples are cooled in desiccators packed in a high-density polyethylene bag and kept at ambient temperature for candy preparation (sensory analysis)

\section{METHODOLOGY}

In the design expert software, the methodology to be followed is to choose the Box - Benken method present in the Response surface methodology. The independent variables are set as the parameters, which are blanching time, osmotic solution, immersion time and convective drying temperature which are to be estimated. Then set the solid gain and water loss as the response activity. Assign it in the Design Expert Software of Version 11

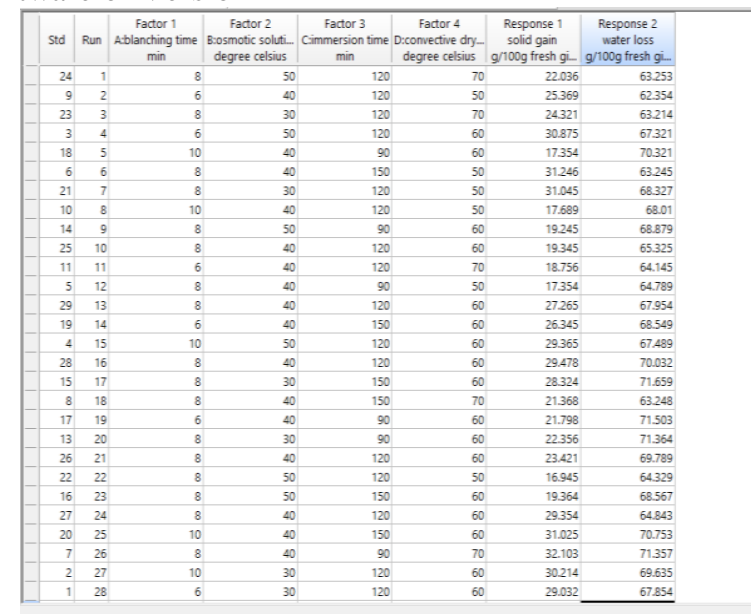

Figure 1: Experimental Design Matrix Developed by Response Surface Methodology

\section{EXPERIMENTAL DESIGN}

The study of combined effect on the independent variable like blanching time, osmotic solution, immersion time and convective drying temperature based on the Box Benken method the experiment was conducted with the quadratic model. These are coded as A, B, C and D as they are the independent variables. In the Box - Benken design a number of 28 combinations having 7 replicates were carried for the chosen variables in the table. The dependent variables (Y) measured for ginger honey candy was solid gain (Y1) and water loss (Y2). The response function is the functions of independent variables which are expressed individually by the dependant variables. The Second-order polynomial is used as a function for the variance were accessed for each factor and they are separated into linear, quadratic and interactive components and they are expressed as follows

\section{RESULTS AND DISCUSSIONS STATISTICAL ANALYSIS}

To establish predictive models from the experimental data for each response variable were shown in the following equation.

Acidity score $\mathrm{Y} 1=44.58371-15.39787 \mathrm{~A}$ -

$1.14700 \mathrm{~B}+1.19847 \mathrm{C}-0.295192 \mathrm{D}-0.033650 \mathrm{AB}+$ $0.038017 A C+0.203612 A D-0.004874 B C+0.029537 B D$ $0.020523 \mathrm{CD}$

$\mathrm{Y} 2=-20.965510-1.96130 \mathrm{~A}-0.704968 \mathrm{~B}-0.282892 \mathrm{C}+$

$4.29928 \mathrm{D}-0.020163 \mathrm{AB}+0.014108 \mathrm{AC}-$

$0.024312 \mathrm{AD}-0.000506 \mathrm{BC}+0.01010093 \mathrm{BD}-0.005471 \mathrm{CD}$

$+0.190477^{2} \mathrm{~A}+0.002019^{2} \mathrm{~B}+0.002019^{2} \mathrm{C}-0.031960^{2} \mathrm{D}$

Were A, B, C, D is blanching time, osmotic solution temperature immersion time and convective drying temperature respectively.

\section{Water loss}

Osmotic solution temperature and blanching time have an interaction effect on Water loss. When the Osmotic solution temperature is at its lowest, water loss is found to increase along with blanching time. But when the Osomatic solution temperature is at its highest the filterability reaches a particular point and at a slower rate, it increases.

fig 1: graphical representation of the blanching time and water loss

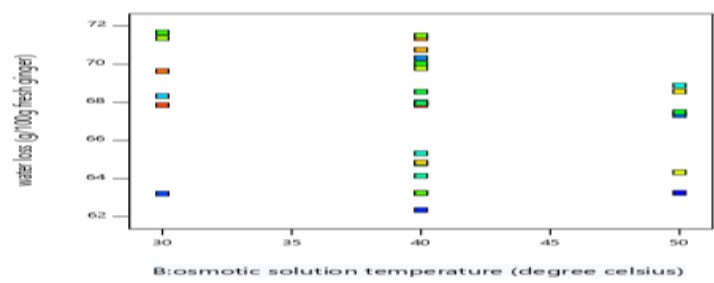

fig.2: graphical representaion of the osmotic solution temperature and water loss.

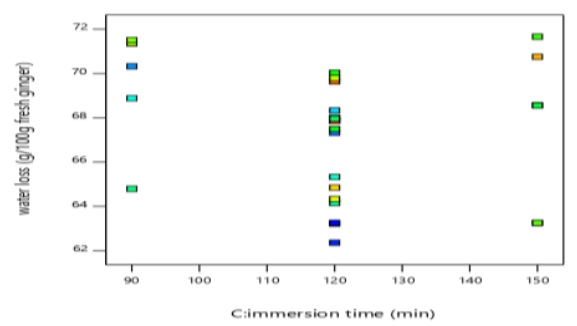

Fig3: graphical representation of the immersion time against the water loss.

Published By:

Blue Eyes Intelligence Engineering

\& Sciences Publication

(C) Cobvriaht: All riahts reserved.

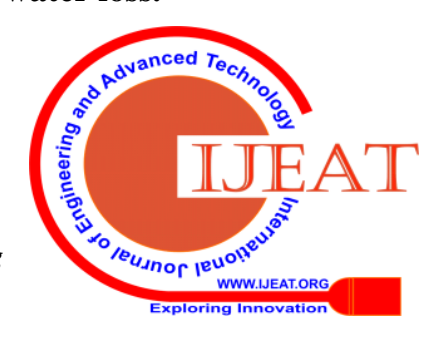




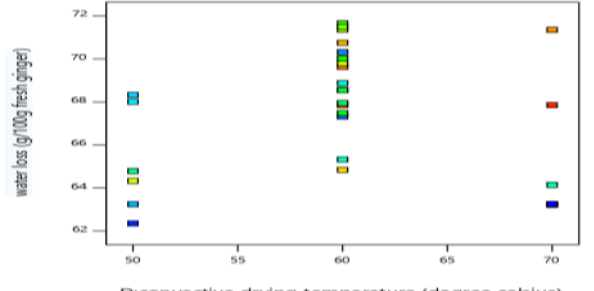

Fig4: graphical representation between the convection drying temoerature and the water loss.

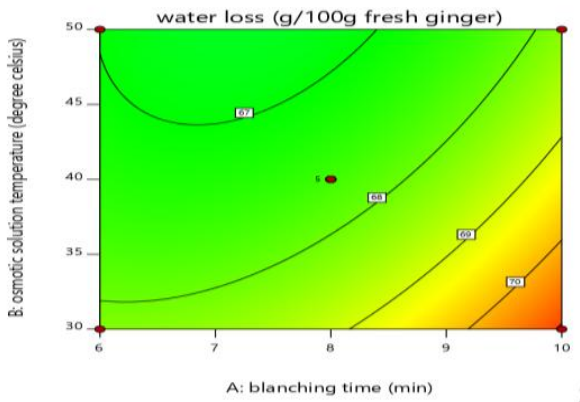

Fig 5:graphical representation between the blanching time and the osmotic solution temperature.

Solid gain:

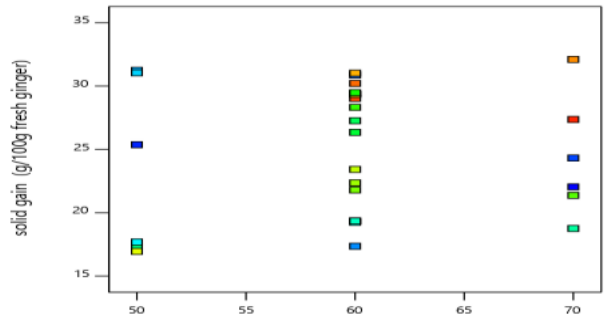

Fig 6: graphical representation between the convective drying temperatures against the solid

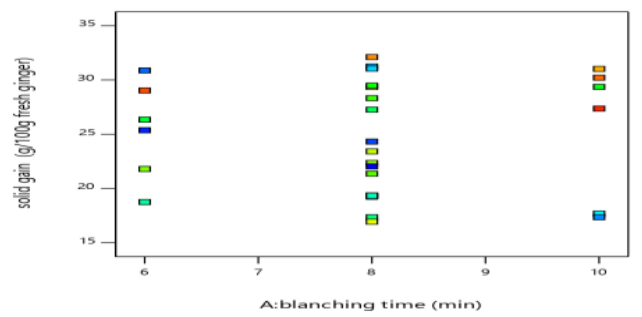

Fig 7: graphical representation of blanchimg time against the solid gain.

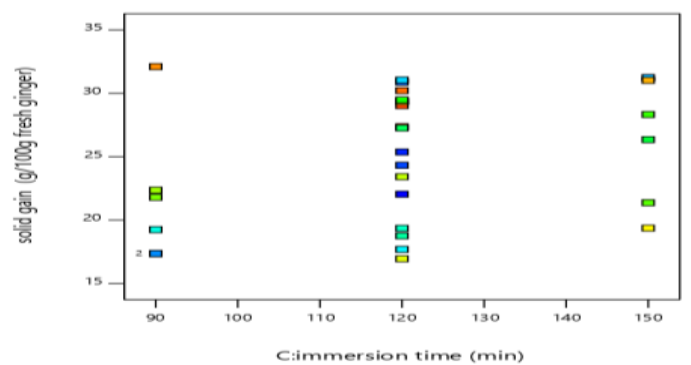

Fig: 8 Graphical representations between the immersion times against solid gain.

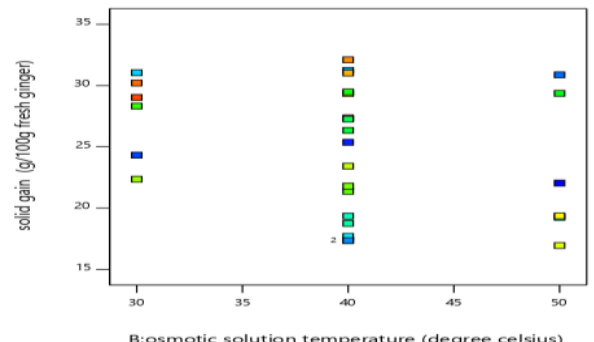

Fig: 9 Graphical representations between Osmotic solution temperature verses Solid gain.

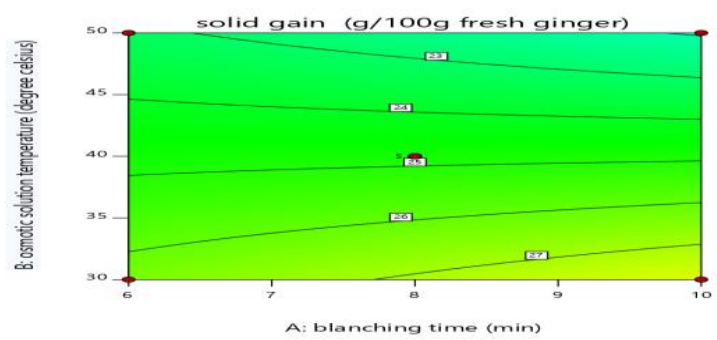

Fig: 10 Graphical representations between blanching time against osmotic solution temperature.

\section{CONCLUSION}

Optimization of honey ginger candy shows a maximum solid gain of $39.4714 \mathrm{~g}$ and a minimum water loss of 68.3457 for 8.39 minutes of blanching time, 39.899 degrees of osmotic solution temperature, immersion time 93.7346 minutes, convective drying temperature. In a similar study shows 7.07 min blanching time, 50_C osmotic solution temperature, 150 min immersion time, and 60_C drying temperature to achieve maximum possible water loss, a solid gain, and overall acceptability.

\section{REFERENCE}

1. Bhattarai, S.; Tran, V.H.; Duke, C.C. The stability of gingerol and shogaol in aqueous solution. Journal of Pharmaceutical Science 2001, 90, 1658-1664.

2. Badreldin, H. Ali; Gerald, Blunden; Musbah, O. Tanira; Abderrahim, Nemmar. Some photochemical, pharmacological and toxicological Properties of ginger (Zingiber officinal Roscoe): A review of recent Research. Food and Chemical Toxicology 2008, 46, 409-420.

3. Langner, E.; Greifenberg, S.; Gruenwald, J. Ginger: History and use. Advances in Therapy 1998, 15, 25-44.

4. Habsah, M.; Amran, M.; Mackeen, M.M.; Lajis, N.H.; Kikuzaki, H.;Nakatani, N. Screening of Zingiberaceae extracts for antimicrobial And antioxidant activities. Journal of Ethnopharmacology 2000, 72, 403-410.

5. Lenart, A. Osmotic-convective drying of fruits and vegetables: Technology and application. Drying Technology 1996, 18(4\&5), 951-966.

5. Pan, Y.K.; Zhao, L.J.; Zhang, Y.; Chen, G.; Mujumdar, A.S. Osmotic Dehydration pretreatment in drying of fruits and vegetables. Drying Technology 2003, 21(6), 1101-1114. 7. Raoult-Wack, A.L.; Guilbert, S.; Le Maguer, M.; Andrios, G. Simultaneous Water and solute transport in shrinking media: Application to Dewatering and impregnation soaking process analysis (osmotic dehydration). Drying Technology 1991, 9, 589-612.

6. 8. Sablani, S.S.; Rahman, M.S.; Al-Sadeiri, D.S. Equilibrium distribution Data for osmotic drying of apple cubes in sugar-water solution. Journal of Food Engineering 2002, 52, 193-199.

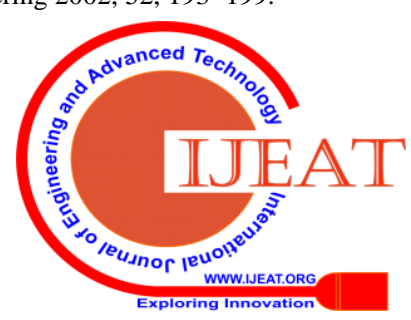

